\title{
Sounds of Waitakere: Using practitioner research to explore how Year 6 recorder players compose responses to visual representations of a natural environment
}

\author{
Linda Locke ${ }^{1}$ and Terry Locke ${ }^{2}$ \\ ${ }^{1}$ Henderson Valley Primary School, 389 Henderson Valley Rd, West Auckland, New Zealand \\ ${ }^{2}$ Arts and Language Education Department, Faculty of Education, University of Waikato, PB 3105, \\ Hamilton, New Zealand
}

milliel@vodafone.ac.nz, t.locke@waikato.ac.nz

How might primary students utilise the stimulus of a painting in a collaborative composition drawing on a non-conventional sound palette of their own making? This practitioner research features 17 recorder players from a Year 6 class (10-11-year-olds) who attend a West Auckland primary school in New Zealand. These children were invited to experiment with the instrument to produce collectively an expanded 'repertoire' or 'palette' of sounds. In small groups, they then discussed a painting by an established New Zealand painter set in the Waitakere Ranges and attempted to formulate an interpretation in musical terms. On the basis of their interpretation, drawing on sounds from the collective palette (complemented with other sounds), they worked collaboratively to develop, refine and perform a structured composition named for their chosen painting. This case study is primarily descriptive (providing narrative accounts and rich vignettes of practice) and, secondarily, exploratory (description and analysis leading to the development of hypotheses). It has implications for a range of current educational issues, including curriculum integration and the place of composition and notation in the primary-school music programme.

I thought seeing what different instruments. (Daniel)

This article is based on a sequence of just five teaching/learning sessions, undertaken by the first author (Linda) with 17 Year 6 (10-11-year-old) recorder-players from a West Auckland primary school in New Zealand. The school has a well-developed, environmental education programme, which was recognised in 2010 by its being awarded a 'Green/Gold' award by the Enviroschools Foundation. ${ }^{1}$ The group was self-selected and met as a special interest group. The students had an enthusiasm for the recorder and were distinguished in their mastery of the instrument in comparison with their peers. In the New Zealand context, the school is atypical in having a specialist music programme. Linda had been employed by the school for 8 years as its music specialist. During this time she had developed a comprehensive music programme, drawing on Orff Schulwerk principles and practices, 
that all students participate in. Within this programme, all students receive 30 minutes recorder tuition from Years 4-6. Tuition in this instrument enables solo and group musicmaking and as well provides the medium through which the reading of conventional musical notation is introduced.

The students who participated in this project were selected on the basis of a 'convenience' sample - students whose dispositions, enthusiasms and prior training made them suitable candidates for the project (Cohen et al., 2005, p. 102). Because of the music programme that they had participated in since Year 1, they had developed a range of skills and knowledge, and engaged in a range of musical experiences. Of relevance to this project, students had had regular, consistent exposure to a wide range of listening examples and regular opportunities to explore and improvise with untuned percussion, mostly in response to written or spoken texts.

Linda prefers to think of this case study as a sliver of pedagogical potential. In action research terms, a problem was posed and analysed (how to engage students in some nontraditional, graphic notational and compositional practices), an intervention designed (as a series of distinct but carefully sequenced sessions), the process monitored and to some extent modified in train and finally reflected on with a view to identifying what might be managed differently at some later time.

What Linda, as the school's music specialist, brought to the project was a belief that as a teacher she didn't necessarily know what children might achieve and was interested in discovering children's horizons of capability in relation to creative music-making. In choosing that 'most abused of the music instruments' (Sargeant, 1971, p. 131), her aim was to extend their horizons in respect of an instrument that they had developed elementary skill in, but which they had hitherto used for conventional purposes. She also brought an emphasis on particular kinds of musical activity, influenced by the Orff Schulwerk approach. A feature of the Orff Schulwerk approach is its emphasis on improvisational processes. Improvisation is integrated into the music programme at the school from the start, and includes exploratory play and finding ways of extending the sound palettes that children have available to them. The project also reflected her desire to find appropriate, meaningful sources of motivation for her students.

What Terry, as a university-based academic and research partner, brought was a curiosity about ways in which children manifest aesthetic knowing in contexts generated by careful teacher planning and scaffolding and how different meaning-making modalities can mutually support and illuminate one another. He also brought a belief in practice as generating theory, especially the classroom-based practices of gifted, critically self-reflexive teachers. He added to this a belief that arts advocacy requires models of effective practice that have been researched, written up and disseminated.

Our research questions were as follows:

1. How do Year 6 students respond to the opportunity to develop a non-conventional sound palette based on the recorder?

2. To what extent are Year 6 students able to conceptualise a response to a painting in musical terms?

3. How does a group of Year 6 students respond to the invitation to produce a structured, group musical composition based on their conceptualised interpretation of a painting? 
The aim of this article is to share the findings of an important practitioner research project and something of the excitement of the process these students engaged in without losing the critical sense of how things might have been done differently.

\section{Children as composers}

In the seminal book Music in the School, Mills (2005) asserts categorically that 'Children are capable of a great deal as composers, if enough is expected of them, and if the tasks that they are set are not so narrow as to constrain them' (p. 40). This was the position that Linda held prior to the commencement of this project. Burnard and Younker (2002) define the act of composing as 'the act of forming or constructing a revised piece created over time' (p. 248). For Barrett (1998a), an emphasis on composition in music education began to move into the mainstream with the rise of the progressive education movement in the 1950s and 1960s (though she acknowledges Orff as a precursor) (1998a, p. 10). Drawing on the work of music educators such as Paynter in the UK, she identifies a range of roles for composition in the classroom: (1) 'creative expression'; (2) a way of 'introducing children to the music and techniques of contemporary composers'; (3) a pedagogy employed 'to promote musical thinking and understanding'; and (4) more exclusively, as a craft attainable only by those with special talent (1998a, p. 13). As Barrett suggests, it is the third of these which appears to be most influential. Paynter (2000) has combined (1) and (2) in telling readers that 'I have long believed that all school students should be encouraged to compose music, not only because it is an essential element of musical education but also because it benefits the general development of imagination and inventiveness' (p. 6).

In addition to the music education literature related to children composing, there is a further literature which investigates the invented notations of children, either in response to given musical pieces or as ways of representing their own compositions. As Upitis (1992) points out, 'Children view themselves as writers long before they view themselves as readers' (p. 53) and the same is true of children who see themselves as makers of music before they see themselves as readers of music. Her interest is in 'how notational systems ... develop in an environment where children were composers, and thus would develop notations as they needed them to record and edit their own works' (p. 52). While Upitis is largely concerned with developmental aspects of children's adoption of notational systems, her research in places strikes a note in relation to this project. For instance, she makes the point that 'Making and playing instruments is inextricably linked with the natural development of music notations' (p. 4). A child using a drum is unlikely to notate pitch. When Upitis makes mention of recorders in relation to invented notation, however, she is viewing the instrument very much in terms of its melodic potential (p. 84), and not in terms of the potential explored in this study for having its 'palette' expanded (see below).

The learning sequence that Linda engaged her recorder-players in was guided by a further set of beliefs about human creativity. These relate to notions of the aesthetic as a primary mode of cognition and adaptation (see, for example, Root-Bernstein, 1996, 2003; Boyd, 2009). This thinking can be encapsulated in three statements:

- The awareness that pattern is central to human meaning-making.

- Form is the aesthetic face of knowledge.

- There is a pleasure in form (Locke, 2010). 
These three statements suggest three phases in aesthetic knowledge production. The first relates to perception or intuition, an awareness of relationship between events or qualities. The second relates to the emergence or embodiment of this awareness into something durable (a painting, poem or equation) or something enacted (a chant or dance) that exhibits qualities such as balance, shapeliness, harmony, elegance that go beyond (but include) the utilitarian. The third is about response to this formal embodiment. The maker herself or himself can take pleasure from his or her own creative acts. But going beyond the individual or group maker, these forms, calling forth from the audience a particular kind of attention, have the potential to produce states that we attempt to describe in words such as 'rapture', 'transport', 'enjoyment', 'delight', 'validation' and even 'Eureka!' These acts of attention, engaged in collectively are powerfully cohesive. Linda's particular interest was this third phase of engaged attention - as something tangible that could be capitalised on as a way of benefiting the learning/creative process.

Root-Bernstein (1996, 2003) argues for a common creative aesthetic shared by scientists and artists alike. More specifically, he argues that:

- 'The most intense aesthetic experiences ... are always multi-modal' (1996, p. 66).

- 'Thinking and feeling are integral' (p. 66).

- Scientific insight comes from what he calls synscientia - knowing in a synthetic way 'being able to conceive of objects or ideas interchangeably or concurrently in visual, verbal, mathematical, kinesthetic, or musical ways' (p. 66).

- A distinction needs to be made between the language used to communicate results in science - words and mathematics - and the 'aesthetic tools necessary to actually do science' (p. 71). The former are inadequate of themselves.

- The arts provide a source of skills and insights that science needs to progress (1996, p. 71) and elaborate 'possible words that can be evaluated for the insights they provide to the real world' (2003, p. 268).

Like Root-Bernstein, we were interested in the idea that the same object (in our case, a work of art) could be made sense of or conceptualised in a fluid way with the mind making simultaneous use of a range of representational meaning-making resources (sound, images, movement, and so on). ${ }^{2}$ The second research question around students conceptualising their response to a painting musically relates to this interest.

In educational contexts, curriculum integration is often talked about in terms of thematic orientations and the need to contest traditional disciplinary boundaries. For example, James Beane (1995) notes that, 'curriculum integration begins with the identification of organizing themes or centers for learning experiences' and 'transcends subject-area and disciplinary identifications' (p. 619). However, we believe there is a more fundamental approach to thinking about curriculum integration, this one based in the integrative workings of the aesthetic as a mode of cognition. This approach is termed 'substantive curriculum integration' by Marshall (2005) who describes it in the following terms:

Substantive integration ... involves making conceptual connections that underlie art and other disciplines. It reveals something of the core principles, structures, and practices of fields by moving beyond the most concrete level (depicting subject 
matters particular to disciplines), to a more abstract level (tapping into the concepts that underlie the disciplines addressed) to the most profound and conceptual level (revealing concepts that are common to art, the disciplines with which it is integrated, and the mind in general) (pp. 228-229).

As we shall see in the next section (Session 2), the students in this project, with carefully 'scaffolded' questions and discussion, were able to move from the auditory to the pictorial (represented in a chosen painting) and back to the auditory, often applying the same concepts to either representational mode. For six years of their primary schooling, these students had been consistently involved in a music programme which offered opportunities for active music-making on a range of tuned and untuned percussion and at times other instruments such as recorder or ukulele. Opportunities for improvisation and the shaping of form and/or other aspects of ensemble material were a feature of the programme. The so-called 'elements of music', as a possible language tool for talking about music, had been introduced partly through a process of osmosis, i.e. the teacher using this particular language, and partly through focused listening exercises which required the students to engage with these concepts.

As Cochran-Smith and Donnell (2006) point out, practitioner inquiry of a systematic kind has a number of 'versions and variants' (p. 503), including action research, teacher research and self-study. Across these versions, they identify a number of shared features: the assumption by the practitioner of a researcher role; the assumption that practitioners embody in their practice worthwhile knowledge; the practice context as site for inquiry; the sense that inquiry is integral to practice and not an optional extra; an expanded notion of what constitutes research validity; 'systematicity' and 'intentionality' (see also CochranSmith \& Lytle, 1993); and an emphasis on dissemination. The practitioner inquiry reported on here exemplifies emancipatory action research, defined by Kemmis and McTaggart (1988) as characterised by such features as: a recursive process of action, reflection and analysis, planning, further action (intervention), reflection and analysis; non-hierarchical collaboration and partnership; and critical self-reflexivity (see also Phillips, 2008; Locke, 2011).

A variety of data were collected or drawn upon to address our research questions. Linda's own observations across the sessions that constituted the intervention (see below) were complemented by the work samples that the students produced. At the end of the project, a questionnaire (Table 3) was administered to the participating students in order to explore their responses to various aspects of the compositional process they engaged in. Observational data were analysed through a process of 'writing out' (cf. Richardson \& St. Pierre, 2005), where we collaboratively reflected on and shaped Linda's reflections on what happened in each session and on the work the students produced in response to the assigned tasks. We present the resulting narrative in the next session, in sufficient detail for our readers to respond critically to the reflections we make.

The responses to each question in the questionnaire data were thematically analysed (Braun \& Clarke, 2006) in order to ascertain the range of responses made to aspects of the intervention and the preponderance of certain kinds of response. We report on the findings from these data in the section on the children's responses to the project. 


\section{The character of the teaching/learning process}

We planned the sequence of sessions prior to the commencement of the intervention. Each session, to be taught by Linda, was attached to one or more learning intentions. In the subsections which follow, we provide a narrative account with commentary and analysis of what happened in each session. For each session, we indicate the learning intention(s) that underpinned the designed activities.

\section{Session One}

Learning intention: Students are prepared to go beyond their usual practices by playing the recorder in an unconventional way and to develop a 'palette' or repertoire of possible sounds.

As an orientation exercise, the students were invited to listen to a piece of contemporary New Zealand music, 'Hine raukatauri', composed by Gillian Whitehead as a duet for taonga puoro (traditional Maori instruments) and flutes. Linda chose this recording because she saw it as exposing students to one composer's attempt to evoke 'sounds of Aotearoa' and could be connected to the local Waitakere environment (including its bird song) that they were themselves very attached to (New Zealand Geographic/SOUNZ, 2007). Students were introduced to the purpose of the project as follows: 'You are going to have the opportunity to make up a piece of music based on a painting by a West Auckland artist that is a response to the Waitakere/West Auckland environment.'

When one comes across references to a sound palette in the music education literature, it is usually with reference to the affordances of digital sound recording and MIDI keyboards (Feldstein, 2001) or of computer music programmes. Reviewing the game Morton Subotnick's Making Music, Farris (2004) writes: 'In Making Music, you work with a sound palette, just as you do in creating art. The sound palette, or instrument palette, has 16 sounds from which to choose to create your music masterpiece' (Sound Palette, paragraph 1). However, a 'sound palette' does not have to be thought of in digital terms, and we deem our use of the term appropriate given the overall purpose of the project (i.e. to compose in response to a painting).

For most of the first session, the students were organised into small groups. They were invited to explore and experiment with unconventional sounds on the sopranino, descant, alto, tenor and bass recorders. They were encouraged to discover as many different ways of playing the instrument as possible and to collaboratively build a 'palette' of 'sounds' These sounds were then shared with other groups.

As mentioned previously, students in this project had elementary music-reading skills as a result of the school's recorder programme. Having developed their sounds, students proceeded to draw a symbol for them in anticipation of the composition task they were to be assigned in Session 3. Sounds produced were not pitched. The students were introduced to the notion of symbols and had no problem with this concept. Their responses were not affected by the knowledge of conventional notation, which to some extent was still a mystery to them. As we see it, they were able to create a symbol for their own sound something far different from developing symbols that would be read by another as connected to the identical sound heard by the symbol-maker. They worked collaboratively 


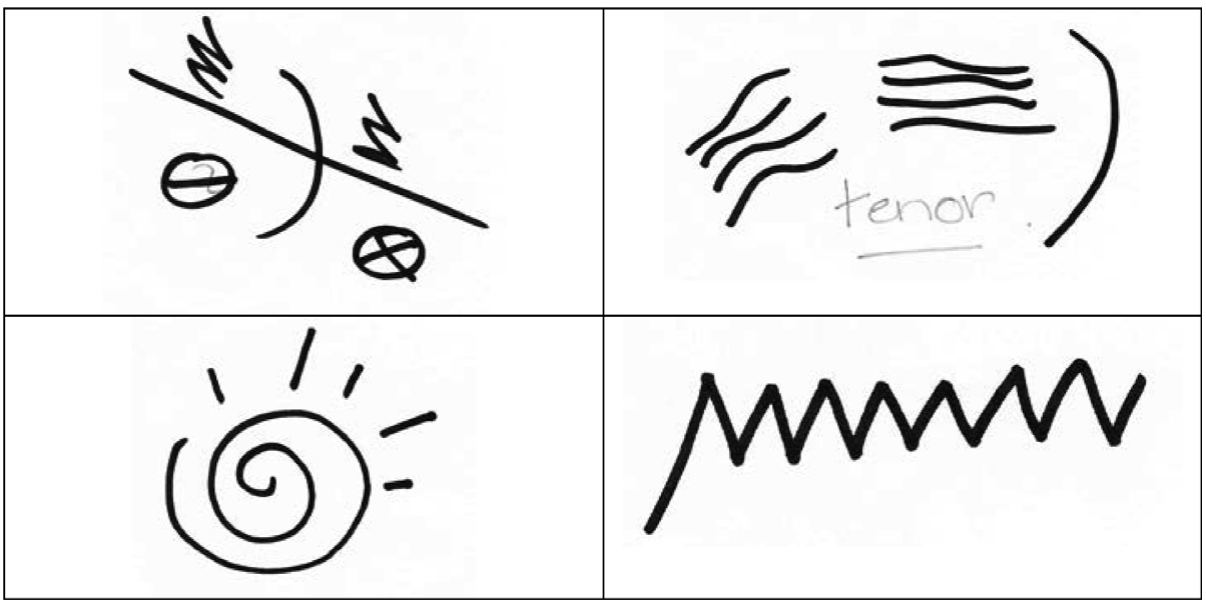

Fig. 1 Children's notations of unconventional recorder sounds

with Linda and one another to refine their representations, which were initially drawn on cards and then transferred to a 'master' list of 17 sounds, which represented the group's 'palette'. (See Fig. 1 for examples of sound notations.)

It needs to be emphasised here that having the students engage in notating their sounds was not related to an assumption that notation is a prerequisite to composition. Such an assumption is at odds with Orff Shulwerk principles. We would concur with Swanwick's assertion that 'musical development neither depends on nor is best observed by translating musical images into notations or words. Such procedures shift the methodological focus from musical development to notational or linguistic development - very different domains' (2001, p. 232). Rather, the activity provided a means of having the sounds 'notated' for future recall. It was also intended as a fun exercise - an invitation to the students to think transmodally by seeing their sounds in visual terms. As it turned out, some did in fact view it an unnecessary chore (yet another writing task).

\section{Session Two}

Learning intention: Students can look closely at the visual properties of an artwork and translate these or re-interpret them in musical terms.

The students brought to this session some prior understanding of the 'elements of music' (for example, pitch, duration, timbre, dynamics, and so on) as a language with which one may talk about sound/music. Before the class commenced, a selection of 14, laminated artworks were prepared based on reproductions of Waitakere paintings by established New Zealand painters (sourced from Harvey \& Harvey, 2006). The pre-selection was done with a view to providing a range of subjects and treatments that the students could later make their own selection from. 
Table 1 Guided musical interpretation scaffold

\begin{tabular}{|c|c|}
\hline Musical element & Prompt questions \\
\hline $\begin{array}{l}\text { Duration } \\
\text { - Beat } \\
\text { - Rhythm } \\
\text { - Metre }\end{array}$ & $\begin{array}{l}\text { Does it suggest a steady pulse or not? Would you associate } \\
\text { anything in this artwork with shorter or longer sounds? Do you } \\
\text { see a pattern that suggests a rhythm or an ostinato? }\end{array}$ \\
\hline $\begin{array}{l}\text { Pitch } \\
\text { - Melody } \\
\text { - Harmony } \\
\text { - Tonality }\end{array}$ & $\begin{array}{l}\text { Would you associate anything in this artwork with higher/lower } \\
\text { sounds? Do you hear more high sounds or low sounds? Do you } \\
\text { see lines of ascent or descent? Do you see colours that blend to } \\
\text { suggest a grouping of sounds? }\end{array}$ \\
\hline $\begin{array}{l}\text { Expressive elements } \\
\text { - Articulation } \\
\text { - Dynamic } \\
\text { - Tempo } \\
\text { - Tone colour }\end{array}$ & $\begin{array}{l}\text { What in the artwork suggests loud? What in the artwork suggests } \\
\text { soft? What in the artwork suggests a fast pace/slow pace? Does it } \\
\text { move from fast to slow or slow to fast anywhere? Do you see } \\
\text { colour contrasts in this artwork? Or contrasts between light and } \\
\text { dark, and harsh and soft, bright and dull, and sharp and fuzzy, } \\
\text { and still and moving? }\end{array}$ \\
\hline Texture & $\begin{array}{l}\text { Are there lots of things happening at the same time? Does you eye } \\
\text { take you from one object to another or do you find yourself } \\
\text { looking at a number of things at the same time? Does you eye } \\
\text { move across the artwork or do you find yourself looking into the } \\
\text { artwork? Do some things seem close to you, while other things } \\
\text { are further away? }\end{array}$ \\
\hline Design/form & $\begin{array}{l}\text { Do you see anything that is repeated in this artwork? What pattern } \\
\text { or patterns do you see in this artwork? Is colour part of this? Is } \\
\text { line part of this? Does this artwork have a central focus? }\end{array}$ \\
\hline Style/mood & How would you describe the mood or atmosphere of this artwork? \\
\hline Context & $\begin{array}{l}\text { Does this artwork remind you of something about the Waitakeres? } \\
\text { place? memory? feeling? }\end{array}$ \\
\hline
\end{tabular}

At the commencement of the lesson, Linda gave a background to the paintings and introduced the class to something of their context. The class discussion addressed such questions as: What inspired them? Who produced them? What flora and fauna are present and how are these represented? Does this remind you of any of your own experiences here in Waitakere?

The next part of the session was taken up with a discussion, the aim of which was to have the students ask themselves: 'What might I hear when I look at a painting?' Linda scaffolded the discussion with reference to Table 1 . The students were guided into giving attention to particular formal aspects of each painting and at the same time make connections with their understanding of musical 'elements'. The next step was to choose, in groups, a painting to view, discuss and 'interpret' along similar lines

The scaffolded discussion provided students with a verbal language and a range of concepts with which to approach a shared interpretation of an artwork which particularly 


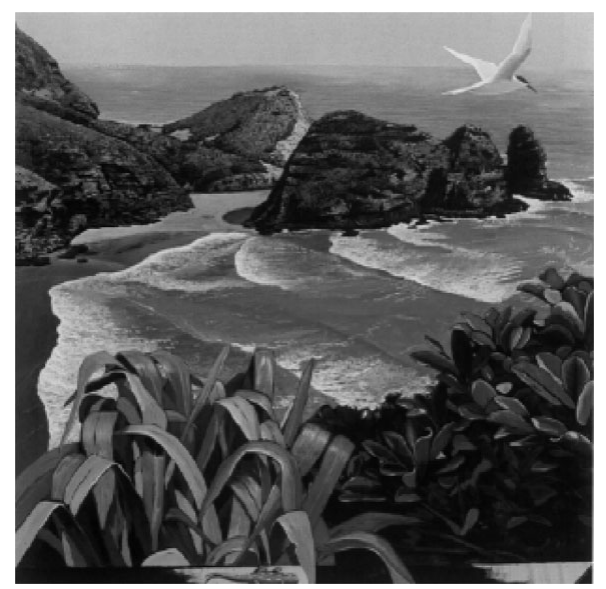

Fig. 2 Russell Jackson. South Piha. 1992

appealed to them. The following paintings were chosen:

- Russell Jackson. South Piha. 1992

- Felicity West. West Coast. 2000

- Geoff Tune. Looking West. 2003

- Don Binney. Under the Moon. 1969-70

Each group produced a response chart in relation to their chosen artwork. (See Appendix 1 for the response chart template.) The group that worked with South Piha, for example (Fig. 2 ), were given a template to record a range of sound-related responses to their selected painting. (Table 2 reproduces their responses with some spellings corrected.)

This should be seen, like any interpretation, as a search for meaning and a way of communicating it. Highly pronounced here is a sense of contrast in the painting, represented in such wordings as: gentle/rough, high/low, wavering/still, fast/slow. As Linda observed, all students were highly engaged in formulating their responses. The latter, of course, were not recipes that would somehow be followed up in the act of composition. Rather they were emblematic of sustained acts of collaborative attention - the result of a mental mapping which would leave its imprint in the course of the compositional process.

\section{Sessions Three and Four}

Learning intention: Students collaboratively compose a soundscape using a range of unconventional sounds to express ideas using a notational system of their own devising.

Prior to the two composition and recording sessions, a 'compositional brief' was designed for the students, which asked them to compose a piece in response to their artwork, calling upon some of the ideas they had already discussed. Their piece was to have:

- an introduction that establishes a mood; 
Table 2 Group response to South Piha (Russell Jackson)

\begin{tabular}{ll}
\hline \hline DURATION & Crashing, bashing \\
Beat & Rustling, whistling \\
Rhythm & Gentle but rough \\
PITCH & High and low \\
Melody & Wavering still \\
Harmony & \\
Tonality & \\
EXPRESSIVE ELEMENTS & Loud (waves) Quiet (animals/wind) \\
Articulation & (Bird/fast) (waves/slow) \\
Dynamics, & (wind slow and fast) (trees whistling slow) - (rustling) \\
Tempo & Light/blue/green/with white \\
Tone Colour & \\
TEXTURE & Thick \\
DESIGN/FORM & Peace: 1. Waves, 2. Trees, 3. Animals \\
STYLE/MOOD & Calm \\
CONTEXT & \\
\hline \hline
\end{tabular}

- sections linked by a bridge which remains the same and is recognisable;

- a coda which revisits the mood of the introduction.

Burnard and Younker (2002) define constraints as 'sets of limitations or conditions that guide the process of decision-making' (p. 248). The brief constrained the students to work within a given structure and functioned in two ways pedagogically. Firstly, it supported students by providing them with a 'ready-made' solution to a compositional problem and made the task achievable. Secondly, and paradoxically, it offered a challenge to their creativity by forcing them to innovate within the terms of the brief and 'liberated' content by imposing a set of structural parameters. ${ }^{3}$ This paradox is summed up eloquently by Stravinsky (1947), as cited by Burnard and Younker (2002): 'My freedom consists in my moving about within the narrow frame that I have designed myself ... the more constraints one imposes, the more one frees one's self of the chains that shackle the spirit' (p. 246).

Students were given a five-line 'score' on which to notate their soundscape, one line per player. Through improvisation and experimentation (with the 'palette' of sounds and techniques previously explored) students collaborated to produce their piece. Figure 3 is the score (with names of contributors removed) of the group who were responding to Felicity West's West Coast, 2000 (Fig. 4). The notes on the right-hand side of the graphic are the children's own description of the sound they were making for a particular line of the score. For a number of reasons, like all of the scores produced, the notation is partial, undeveloped and unrefined.

As indicated earlier, the students became frustrated with the chore of notation. They found that their memories served them well enough as a place to store the work in progress. Moreover, because the urge to continue the exploratory journey was stronger than the urge to ' $f \mathrm{ix}^{\prime}$ their composition in notated form, they preferred to give up on the job of notation, 


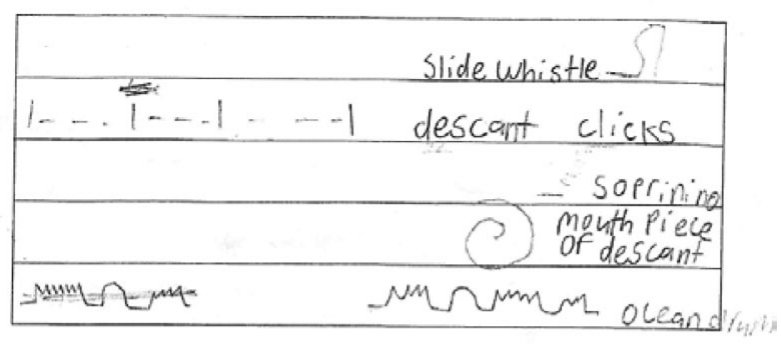

○

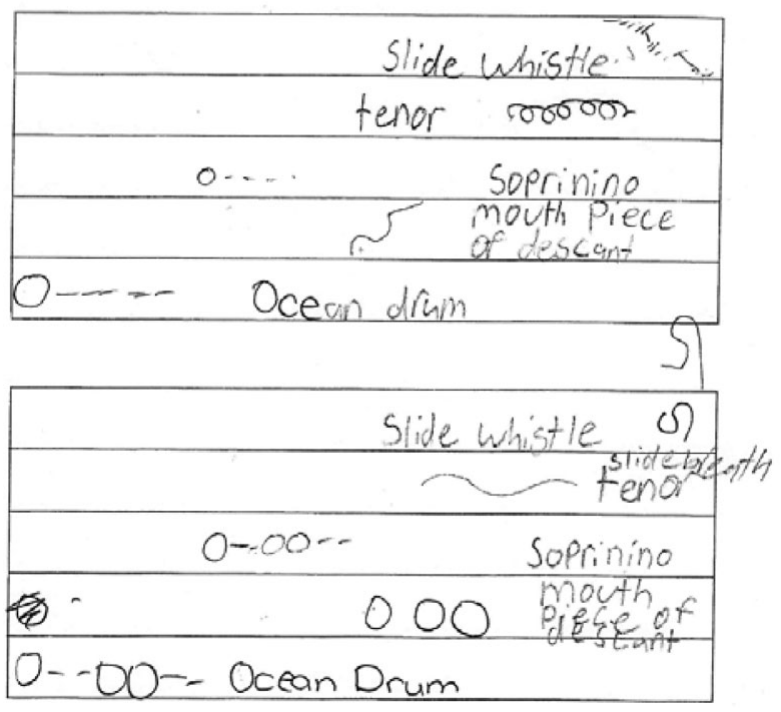

\section{$\Omega$}

Fig. 3 Partly notated piece in response to Felicity West's West Coast, 2000

preferring to continue the process of refinement without scoring their modifications. In addition, they worked on their compositions in the school music room, where an array of percussion and other instruments were available for use. This group, like others, found the desire to add percussion effects using other instruments and objects irresistible; the task parameters were expanded to accommodate this desire. Burnard (2000), shows how 'creative intention' is a key 'determinant of the ways of experiencing improvising and composing' for young students (p. 21). In this instance, the creative intention was a spur to these students' desire to continue the process of exploration and selection (stages Burnard and Younger (2002) term 'incubation' and 'illumination') without the need to ' $\mathrm{fix}^{\prime}$ their composition in the form of a score.

Prior to the project, it had been our somewhat ambitious aim for the students to create a graphic score for their piece devising symbols to represent sound and order these appropriately in their score. Kid Pix and PowerPoint programmes would be used to record 


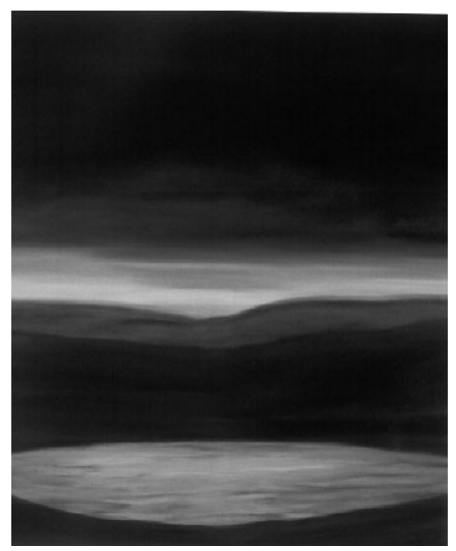

Fig. 4 Felicity West. West Coast. 2000

their ideas. In retrospect, this aim was not properly thought through. As we discovered, for good reason, the urge to compose took precedence over the plan to notate. In the final analysis, the notational symbol system proved redundant, since the students had little difficulty remembering their pieces, which they continued to refine, right up to the point of recording them.

We were both present for the recording session, which took place in the music room of the school. All students arrived on time, highly motivated and totally concentrated on the task in hand. As each group arranged itself in readiness for a final rehearsal and rendering of their piece, non-players sat in an engrossed and supportive silence. During the rehearsal phase, occasional reminders and last-minute refinements were made to pieces, which were clearly understood by all participating players. No scores were in evidence.

While our focus for this little project was process, the children themselves communicated a sense that they had created a product that they were keen to share. (In fact, all demanded copies of a DVD of the pieces.) Each piece had its own distinct qualities, of course, and we mention just one of them here for brevity's sake. We'll call this group Emily, Melissa and Daniel. The painting they seized upon was Geoff Tune's Looking West, 2003 (an abstract painting that other groups shied away from) (see Fig. 5).

In their response notes to this painting, the group identified movement suggested by yellow 'scratchy lines', lots of contrasts in the shapes (small stars/white dots/orange arrows, and the circle as the strong centre). In their recording [see accompanying file], Emily played alto recorder in a manner she described as 'like a bird' and also cowbells to evoke footsteps. Daniel struck the gong (described by him as 'like thunder') at the beginning and the end of the piece inspired by the central blue circle in the painting. He used driftwood to strike bamboo, stone and shell, evoking the natural world and both the order and the contrast suggested by the painting. He also used the mouthpiece of the soprano recorder. Melissa played a melody during the introduction and coda of the piece using the upper register of the descant recorder, that she thought evoked the upper part of the painting (travelling among the stars). In the middle sections of the piece she played cowbells with rubber beaters. 


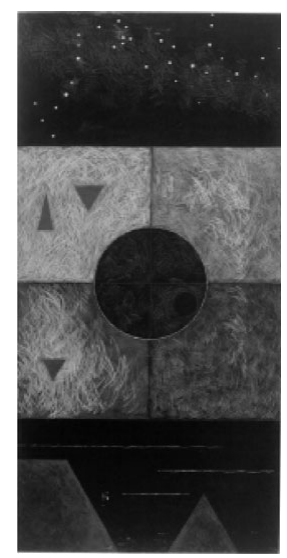

Fig. 5 Geoff Tune. Looking West. 2003

The narrative we have just shared, drawing on teacher observation and the work the students did, sheds some light on each of our three questions. Students readily understood the concept of non-conventional notational symbol and, in developing their own, were not deterred by the knowledge of conventional notation they already had. Their symbols were idiosyncratic - adequate as a personal cue but 'unreadable' to others. While the exercise was designed by us for both fun and as a compositional aid, it was clear that for some students it was something of a chore.

The students' prior knowledge from their music programme of a range of elements of music 'tuned' them to conceptualise a painting in musical terms. This knowledge of elements, systematic teacher modelling and scaffolded cueing, and focused, imaginative engagement, appeared to be determining factors in their successful production of a musical response to their selected painting. The compositional brief, which contained both limitations and conditions (Burnard \& Younker, 2002), was facilitative in respect of the compositional decision-making students engaged in, drawing on their devised palette of sounds and the sound concepts developed in response to their group's painting. However, while the students were compliant in notating their compositions drawing on their devised symbols, a number found the task tedious and committed their 'work in progress' to memory with ease. Some of them also found the recorder restriction limiting as their ideas developed. As we noted earlier, the urge to compose took precedence over the requirement to notate. During the recording session, it was clear that the students had developed a strong commitment to their group product and were keen to both perform and to hear the performances of others.

\section{The children's responses to the project}

At the end of the project we took the opportunity to invite the children to share their responses to aspects of this intervention via a short questionnaire (see Table 3) for the completion of which we had obtained their consent and also the consent of the principal. In what follows, no child is identified by his/her actual name. 
Table 3 Student response questionnaire and links to research questions

Question 1: Why did you agree to be part of this project? What did you think you would get out of it?

Question 2: (a) What did you enjoy most in the sessions where you explored making different sounds from recorder?

(b) Is there something you didn't like about this session. [Relates to RQ 1]

Question 3: In Session 2, Ms Locke reviewed some musical terms to help you respond to paintings. Write one thing you learnt that you thought was really interesting. [Relates to RQ 2]

Question 4: What is your opinion about the following sentence. "In some ways, a painting is like a piece of music." Do you agree? Disagree? [Relates to RQ 2]

Question 5: (a) What did you enjoy MOST about the composition work that you did?

(b) What did you enjoy LEAST about it? [Relates to RQ 3]

Question 6: Is there something you would have liked Ms Locke to have done differently when you think back over this project?

The students agreed to be part of the project for a range of reasons, the most common of which (9 students or 53\%) was that they thought it would be fun. Jack stated that: 'I agreed to be a part of it because I love music and it just sounded really fun to do.' Jack's first reason, that he loved music, was echoed by three others in the group. Emily commented that: 'I agreed to being a part of this project because I thought it would be fun to do it. I thought I would get a cool piece of music I made.' Four of the participants (including Emily) indicated that their desire to be involved related to the prospect of actually composing music. Melissa, for example, commented: 'I thought it would be fun to record and make up music with a group.' The other major reason cited for becoming involved related to the anticipation of learning of some kind: Patricia said it 'would make my music ability better', while Charlotte 'really liked the idea of learning different sounds'.

\section{Developing a non-conventional sound palette}

The first part of Question 2 asked students what they enjoyed most about Session 1, with its focus on students developing and notating unconventional sounds from the recorder. The most common reason for enjoyment related to the theme of novelty ( 7 students or $41 \%$ ). Students enjoyed an expanded sense of the range of sounds the recorder could make. A typical comment came from Wally who said: 'I enjoyed making sounds on the recorder that I didn't know about before.' Taylor talked about 'inventing original sounds with recorder'. Another common theme (five students) related to the freedom to experiment. Patricia noted: 'I enjoyed doing anything with your recorder rather than playing notes.' Charlotte noted: 'I like to muck around with the high and low sounds, e.g. bass, tenor.' A third theme mentioned by two students related to the enjoyment that comes from combining sounds to produce unusual textures.

The students were also asked to comment on aspects of this session that they didn't like. Eight students (47\%) had no reservations. However, the remaining nine offered a range 
of negative comments. Three of these pertained to group dynamics (e.g. 'Sometimes other kids in my group could get a bit bossy.'). Two students objected to having to notate/write ('Sometimes when we had to write down our symbols. It was hard.'). One student was unhappy about being restricted to recorder, another wanted more time and another felt that she had come to the activity without adequate preparation.

\section{Conceptualising responses to a painting in musical terms}

Question 3 related to Session 2, where students were engaged in reading one or more paintings. They were asked to say something they had learned that they found interesting. The most common theme (seven students) from the 13 who responded to this question ${ }^{4}$ related, unsurprisingly, to the learning of a technical musical language to talk about the paintings themselves. Jack wrote: 'I never knew there could be so much different word [sic] related to music.' Daniel wrote cryptically and in a way which suggests engagement in the kind of synaesthetic knowing summed up in the term 'synscientia' (Root-Bernstein, 1996, p. 66) discussed earlier: 'I thought seeing what different instruments.' Related to this theme, three students focused on one or more specific concepts that they found helpful. Sandra referred to 'the bright sounds'; Patrice said: 'I learnt what tone, beat and rhythm meant'; and Taylor talked 'All the different beats and tones you need to make music.' A second theme represented by two students related to the sense that a painting can be responded to in a variety of ways. Charlotte summed up this theme by commenting: 'That music has so many different sounds and ways to read it.'

We imagine the students felt somewhat constrained to agree with us in respect of Question 4. Unsurprising, they all agreed that 'In some ways, a painting is like a piece of music', though there were differences in modality. (Emily said she agreed 'in some cases', while Billy asserted that he agreed 'in every way possible'.) What was interesting to us was the language some of the students used to support their agreement. We offer three of the more interesting statements: Mandy: 'I agree because it has depth like a piece of music. They are both art as well. But they sometimes can feel different'; Jack: 'I do agree because some different instruments and sounds can make you think of different parts of a picture (like waves for instance)'; Lope: 'I agree. Because sometimes a painting can really feel like it's playing music to you.' Mandy is recognising in her statement that there are dimensions in terms of which different art forms can be compared ('depth') while maintaining distinctive tonalities. Jack is drawing attention to a kind of synaesthetic emotional 'equivalence' between different meaning-making resources (visual and aural). A similar sense to Jack's statement is conveyed by Lope.

\section{Producing a structured group musical composition}

What did the students like most about the composition work (Question 5a)? The most common response (10 students: $59 \%$ ) conveyed a sense of satisfaction at the actual sound that had been collectively achieved. Jack wrote: 'It was very hard work but in the end I was absolutely impressed with the songs we made.' A number of students commented on the qualities of the sound-mix. For example, Taylor referred to 'Making interesting but almost weird sound [sic] and putting them together.' Clara talked about 'Getting to 
work with the different sounds than I normally get to muck around with.' A second major theme (six students) was the recording session itself: Lope, for example wrote: 'Definitely making the soundscape then recording it that was awesome.' Emily enjoyed 'Playing to the whole group'. A third theme identified in the analysis of responses was the collaborative aspect of the compositional exercise. Huia commented: 'We sounded great together, and working with a group is enjoyable and memorable'. Finally, taking up a theme mentioned previously, Melissa commented that, 'You could play what you liked without being told off.'

What did students like least about the composition work (Question 5b)? Of the 14 students with a comment to make, four referred to the challenges of working in a group, e.g. 'It was hard for my group to listen to each other because we all had so many different ideas' (Jack). Two students were unhappy with the time constraints, wanting more time to work on their compositions. Two complained about having to make a choice between involvement in the project and fun activities in their regular classes. Two referred to the demands of having to write. A number of one-off comments of interest to the researchers were made. One student disagreed with her group's choice of painting ('not vibrant enough'), while another found it difficult to 'come up with sounds different from everyone else's' (Wally).

Finally, Question 6 asked students to identify something that would have liked Linda to have done differently. Ten students indicated that they couldn't think of anything. (Jack wrote: 'No she was a perfect teacher and helped us work out our arguments.') Of the six that made suggestions for changes, two indicated that they would have liked a broader palette of available sounds. For example, Sandra asked for 'sounds other than recorder'. A third student indicated that more control was needed over group processes, while Mandy wrote: 'Maybe we could have written an individual piece of music and then compared it to other peoples to make a longer varified [sic] piece.' The remaining two students offered Linda pedagogical feedback: Charlotte wanted more explanation about the 'different sections in the music', while Emily cautioned Linda about 'talking too long because if we have an idea we would usually forget it'.

In summary, most of the students agreed to participate in this project because they thought it would be fun or because they liked the idea of composing music. Their reasons for enjoying developing a non-conventional, recorder-based sound palette, included the novelty and potential for discovery of the activity, the freedom to experiment and the exploration of textural possibilities. While a significant majority enjoyed the activity, a small majority have a number of negative responses related to such things as group processes, the chore of writing down, being restricted to the recorder and the lack of time. In respect of the second research question, the most common learning commented on by students was an enhanced ability to view a painting in visual terms, followed by the possibility of a painting's being able to be read in a variety of ways. While students concurred with the proposition that in some ways, a painting is like a piece of music, they varied in the force of the agreement. A number, however, were able to use language applicable to both media in framing their responses. Finally (RQ 3), students enjoyed the composition task because of the sense of satisfaction the final product gave them, the act of recording their piece and its collaborative nature. However, this satisfaction, for some was counter-balanced by the challenges of working effectively in a group, with time constraints and in a withdrawal 
situation where they were missing out on activities engaged in by other members of their classes.

\section{Conclusion}

At the start of this article, we mentioned Linda's description of the project as a sliver of pedagogical potential - as an opportunity to investigate student responses to a teaching/learning sequence that had not be attempted before. Looking back on what the children achieved, a number of things have been reinforced for us. The first of these is the capability of these students to engage in aesthetic thinking, both in the broad, generic sense used earlier in the article, and in the narrower sense of meaning-making and decisionmaking in the context of arts discipline-specific art-making (see Plummeridge, 1999). After discussing a range of approaches to the aesthetic (sensory, cognitive, and so on), Barrett (1998b) proposed a view of 'aesthetic thinking and decision-making in the educational context as thinking intrinsic to an art form', that is 'cognitive in character and primarily, but not exclusively, concerned with issues of form and structure in an art work or experience' (p. 59).

From the second session to the moment of recording, the students in this project were engaging in aesthetic decision-making along the lines that Barrett suggests. Through active involvement with the paintings by Geoff Tune and others, they were experiencing artworks which were responses in visual form to the natural environment familiar to them, both as a result of their geographical living circumstances and the 'enviro-school' programme at the school they attended. By exploring the possible application of a range of musical terms to these paintings, they were able to construct interpretations of their own which gave them a range of formal ideas, which could then inform their own compositions.

This awareness leads to a second point. While we would concede that a number of the children's decisions were made extempore and intuitively in the process of composition, the engagement in aesthetic decision-making was facilitated by the scaffolding Linda used as a way of fostering a conceptual vocabulary for thinking about two art forms. In this respect, the project can be seen as reinforcing the value of metacognition as a component of learning and as crucial for teachers wanting to help students improve their compositional products (see Paynter, 2000). Student responses to Question 3 reflect their satisfaction at having had their arts vocabulary enhanced. We can see how this vocabulary acquisition, evidenced by Mandy's use of the term 'depth', enabled her to both perceive an element in a painting and apply it in a musical composition. This vocabulary acquisition facilitated their ability to reflect on their own learning processes and has the potential (largely unrealised) to contribute to their refinement of their compositional products.

Thirdly, we concur with the view of Mills (2005) on the importance of task design. These children were not given a free rein. Rather they were presented with a problem (how to interpret a painting musically) and a set of structural constraints for their composition. The project reinforced our belief that a combination of possibility and constraint is a stimulus for creativity and not a dampener of it.

Fourthly, the nature of the project reinforced the value of collaborative composing. However, as indicated by responses to Question 5, four students referred to the challenges of working in a group. Drawing on Engström's Activity Theory, Burnard and Younker (2008) 
have highlighted the complex of factors operating when groups compose collaboratively. They find that 'task-directed-talk (affirmed through task-directed-action) appears to serve as the most accessible medium of interaction within activity systems of group composing' (p. 73). If this is the case, then the role of the teacher as facilitating, modelling, teaching and monitoring interactive processes becomes a vital determinant of the outcome of the collaborative compositional process.

Fifthly, the project confirmed for us that children are 'wired' to make (aesthetic) sense of the world multimodally and to move between modes in the process of composing responses to the world of nature and artifacts and in the process of composing their own art works. In Root-Bernstein's (1996) terms, these students were quite capable of practising synscientia - knowing in a synthetic way (p. 66). In this respect, the project confirmed the potential of the approach to integrating curriculum (substantively), as suggested by writers like Marshall (2005). Effectively, students in the project were given an opportunity to engage in a range of representational (including notational) systems, encoding sounds in the construction of a palette, decoding a painting and then (to an extent) using their invented notational system to encode their compositions. As designers of this intervention, we agree with Upitis' assertion that, 'Children have a remarkable ability to move in and out of various systems, and by doing so, they learn more about all of the systems they encounter and invent' (1992, p. 54).

Overall, then, these students responded eagerly to opportunities offered to explore freely the potential of a familiar instrument to produce a range of sounds. They enjoyed the challenge, and mostly enjoyed the idea of devising symbols for the sounds they had discovered. With a relatively small amount of scaffolding, they began to develop a way of conceptualising a painting in a range of musical terms, and we have no doubt that this enhanced the kind of attention they brought to the act of looking at a painting. While some felt restricted in being asked to limit themselves to recorder-generated sounds, they responded enthusiastically to the challenge of working together to produce a composition that translated their conceptualisations of a chosen painting into their own musical artwork. In the process of devising, their notated symbols became something of an irrelevance to them, as they focused on what they saw as the main object of the exercise - the chance of sharing their work with their classmates and having their work recorded.

\section{Considerations for future practice}

Having said this, a number of potentials were not realised in this project. The compositions all represented promising starts, but would have benefitted from systematic and reflective development within the given structure. Given the limited utility of the graphic symbols developed by the students, it remains an open question with us regarding the role these symbols might play in a recursive process of further improvision/exploration, refinement and evaluation of these pieces. It would have been a valuable exercise for the students also to have had the opportunity to re-engage with the paintings in these subsequent acts of reflection and revision (perhaps with input from the artists themselves, all of whom have subsequently expressed a willingness to involve themselves in an extended version of this project) and to have had the satisfaction of abandoning 5 their compositions at a point 
dictated by a sustained process and not by the exigencies of a busy school timetable and the conflicting demands of curricular and co-curricular programmes.

\section{Considerations for future practitioner research}

This has been a small case study involving practitioner research in the New Zealand, state, primary-school setting. The specific classroom practices that this project emphasise include:

- engaging students in exploratory activities which enable them to expand the sound palettes they view as appropriate for compositional work;

- engaging students in activities which involve them in moving between representational modes as a way of encouraging and reflecting on 'synthetic' thinking;

- scaffolding students in the use of language that enables them to reflect on their own (and others') creative process and informs their arts discipline-specific decisionmaking;

- designing composition tasks characterised by constraint and possibility.

As indicated earlier, the role of notation in all of this remains an open question with us and a topic that requires further research. Like Paynter (2000), we are interested in finding the means of researching ways of involving students in more sustained compositional enterprises so as to find ways of building in effective ways of having them evaluate and refine their own products. In particular, how might a communicable, discipline-specific aesthetic be developed to assist students in the process of revision? Finally, we believe that further practitioner research needs to be focused on the ways students might be encouraged to explore the relationship and interplay between ways their world is realised in sound and sight.

\section{Acknowledgements}

We thank the following painters who warmly and enthusiastically agreed to us reproducing a version of their work to share with readers of this article: Don Binney, Geoffrey Tune, Felicity West and Russell Jackson.

\section{Notes}

1 See http://www.enviroschools.org.nz/

2 As Plummeridge (1999) points out, the term 'aesthetic' is prone to a number of varying usages in debates around the nature of and rationale for music education. We are aware of the debates between those who would justify music education on 'aesthetic' grounds (Reimer and others) and 'praxialists' such as David Elliott and Thomas Regelski (1998) (see McCarthy \& Goble, 2005 for an overview of this debate). In this article, however, we have eschewed the terrain of this debate. Our use of the term 'aesthetic' relates most closely to the first of three, widespread usages Plummeridge identifies in his useful article, namely the generic (Deweyan) sense of 'an essential qualitative aspect of all those genuine experiences which contribute to the process of personal growth' (p. 116). However, our belief that the aesthetic is at the heart of the kind of human meaning-making that allows for creativity 
and innovation is not to say that it is not the special provenance of the arts. This we take to be an implication of Root-Bernstein's writings. It is an implication that is important for those of us who take up the cause of arts advocacy, especially in contexts where educational policy appears to favour a rationalistic approach to learning (see Claxton, 2000) linked with the espousal of outcomes-based testing and assessment.

3 Such an approach is widespread. An example from literature teaching, is Kenneth Koch's well-known use of formulae derived from 'great poems' as a stimulus to young children's creative writing (Koch, 1973).

4 Two respondents had not been at this session, one could not think of a learning, and one response related to the composition session.

5 The poet Paul Valéry is famously reported to have said that a poem is never finished, merely abandoned. This stage of the composing process is termed 'verification' by Burnard and Younker (2002).

\section{References}

BARRETT, M. (1998a) Researching children's compositional processes and products: Connections to music education practice? In B. Sundin, G. McPherson \& G. Folkestad (Eds.), Children Composing (pp. 10-34). Malmö: Malmö Academy of Music, Lund University.

BARRETT, M. (1998b) Children composing: A view of aesthetic decision-making. In B. Sundin, G. McPherson \& G. Folkestad (Eds.), Children Composing (pp. 57-81). Malmö: Malmö Academy of Music, Lund University.

BEANE, J. (1995) Curriculum integration and the disciplines of knowledge. Phi Delta Kappan, 76, 616-622. BOYD, B. (2009) On the Origin of Stories. Cambridge, MA: Harvard University Press.

BRAUN, V. \& CLARKE, V. (2006) Using thematic analysis in psychology. Qualitative Research in Psychology, 3, 77-101.

BURNARD, P. (2000) How children ascribe meaning to improvisation and composition: Rethinking pedagogy in music education. Music Education Research, 2, 7-23.

BURNARD, P. \& YOUNKER, B. (2002) Mapping pathways: fostering creativity in composition. Music Education Research, 4, 245-261.

BURNARD, P. \& YOUNKER, B. (2008) Investigating children's musical interactions within the activities systems of group composing and arranging: an application of Engeström's Activity Theory. International Journal of Educational Research, 47, 60-74.

CLAXTON, G. (2000) The anatomy of intuition. In T. Atkinson \& G. Claxton (Eds.), The Intuitive Practitioner: On the Value of not always Knowing what One is Doing (pp. 32-52). Buckingham: Open University Press.

COCHRAN-SMITH, M. \& DONNELL, K. (2006) Practitioner inquiry: blurring the boundaries of research and practice. In J. Green, G. Camilli \& P. Elmore (Eds.), Handbook of Complementary Methods in Education Research (pp. 503-518).

COCHRAN-SMITH, M. \& LYTLE, S. (1993) Inside/Outside: Teacher Research and Knowledge. New York: Teachers College Press.

COHEN, L., MANION, L. \& MORRISON, K. (2005) Research Methods in Education. New York: Routledge Falmer.

DOLLOFF, L. (2005) Elementary music education: building cultures and practices. In D. Elliott (Ed.), Praxial Music Education: Reflections and Dialogues (pp. 281-296). New York: Oxford University Press.

FARRIS, D. (2004) Review: Morton Subotnick's Making Music. Retrieved 22 October 2009 from the Golden Triangle PC Club website at http://www.gtpcc.org/gtpcc/makingmusic.htm.

FELDSTEIN, S. (2001) Music education and technology: Past, present, and future. Teaching Music, 9(3), 26-30. 
HARVEY, B. \& HARVEY, T. (2006) Waitakere Ranges: Ranges of Inspiration. Waitakere City: The Waitakere Ranges Protection Society Inc.

KEMMIS S. \& MCTAGGART R. (Eds.) (1988) The Action Research Planner. Geelong: Deakin University.

KOCH, K. (1973) Rose, Where Did You Get That Red? New York: Vintage.

LOCKE, T. (2010) Minding the aesthetic: the place of the literary in education and research. Waikato Journal of Education, 15 (3), 3-16.

LOCKE, T. (2011) Critical literacy as an approach to literary study in the multicultural, high-school classroom. English Teaching: Practice and Critique, 10 (1), 119-139.

MCCARTHY, M. \& GOBLE, J. (2005) The praxial philosophy in historical perspective. In D. Elliott (Ed.), Praxial Music Education: Reflections and Dialogues (pp. 19-51). New York: Oxford University Press.

MARSHALL, J. (2005) Connecting art, learning, and creativity: a case for curriculum integration. Studies in Art Education, 46, 227-241.

MILLS, J. (2005) Music in the School. Oxford: Oxford University Press.

NEW ZEALAND GEOGRAPHIC/SOUNZ (2007) Sound Barrier (Double CD). New Zealand Geographic/SOUNZ.

PAYNTER, J. (2000) Making progress with composing. British Journal of Music Education, 17, 5-31.

PHILLIPS, K. (2008) Exploring Research in Music Education and Music Therapy. New York: Oxford University Press.

PLUMMERIDGE, C. (1999) Aesthetic education and the practice of music teaching. British Journal of Music Education, 16, 115-122.

REGELSKI, T. (1998) The Aristotelian bases of praxis for music and music education as praxis. Philosophy of Music Education Review, 6, 22-59.

RICHARDSON, L. \& ST. PIERRE,E. (2005) Writing: a method of inquiry. In N. Denzin \& Y. Lincoln (Eds.), The Sage Handbook of Qualitative Research (3rd edn.) (pp. 959-978). Thousand Oaks, CA: Sage.

ROOT-BERNSTEIN, R. (1996) The sciences and arts share a common creative aesthetic. In A. Tauber (Ed.), The Elusive Synthesis: Aesthetics and Science (pp. 49-82). Dordrecht: Kluwer.

ROOT-BERTSTEIN, R. (2003) The art of innovation: polymaths and universality of the creative process. In L. Shavinina (Ed.), The International Handbook On Innovation (pp. 267-278). New York: Pergamon Books.

SARGEANT, P. (1971) Recorders in the classroom. In D. Symons (Ed.), Report of Proceedings of the Second National Conference: New Perspectives in Music Education. Nedlands, WA: Australian Society for Music Education with assistance from the Australian Council for the Arts (pp. 131-134). Retrieved 5 May 2010 from http://search.informit.com.au/documentSummary;dn=611900497142319; res=IELHSS.

SWANWICK, K. (2001) Musical development theories revisited. Music Education Research, 3, $227-242$.

UPITIS, R. (1992) Can I Play You My Song? The Compositions and Invented Notations of Children. Portsmouth, $\mathrm{NH}$ : Heinemann. 


\section{Appendix 1}

\section{Name of painting}

Look for colour line, shape, contrasts, materials, design, that you can interpret in musical terms as below

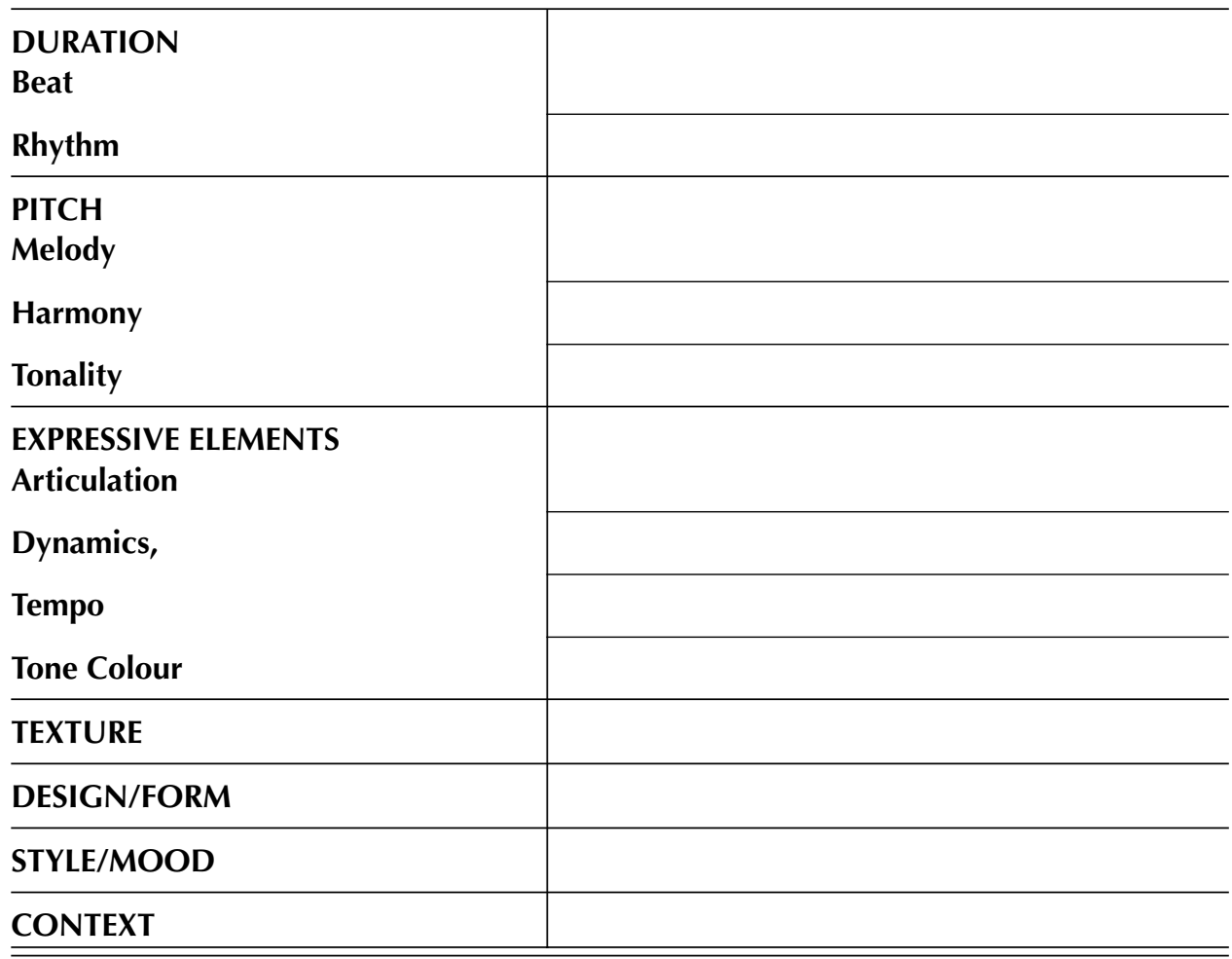

